\title{
In Memoriam: Prof. Dr. J.M.J.J. Vossen (1937-2019)
}

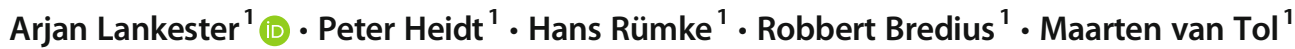

Received: 10 July 2019 / Accepted: 11 July 2019 / Published online: 25 July 2019

(C) Springer Science+Business Media, LLC, part of Springer Nature 2019

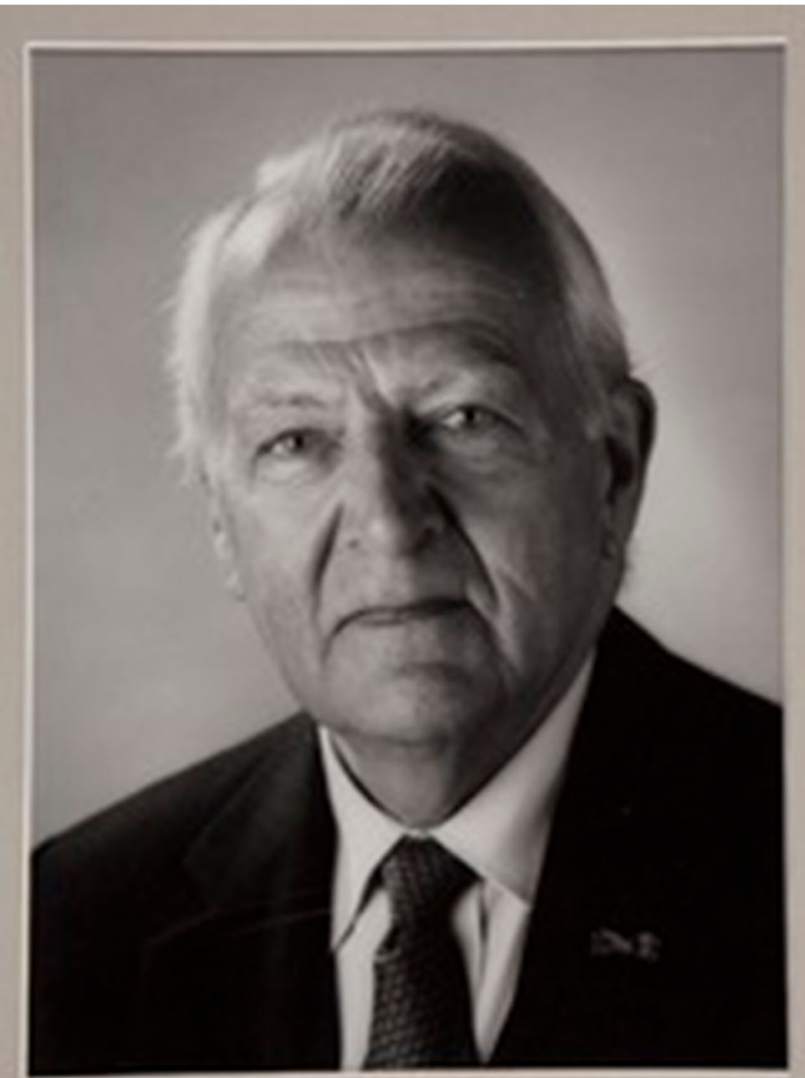

Prof. Dr. J.M.J.J. Vossen
Jaak Vossen passed away on April 30, 2019, at the age of 81 years. He studied medicine in Leuven (Belgium), and after

Arjan Lankester

a.lankester@lumc.nl

1 Pediatrics, Leids Universitair Medisch Centrum, Albinusdreef 2, Leiden, Netherlands his residency, he worked as a pediatrician in the Academic Hospital in Leiden from 1968, and from 1979 to 2002 as a professor-holding a chair in pediatric immunology.

Together with pediatricians J. de Koning and L.J. Dooren and transplantation pioneers Dick van Bekkum and Jon van Rood, Jaak was involved in the first successful stem cell transplantations (SCT) in children in Europe. The first SCT procedures were performed in children with severe immunodeficiencies and aplastic anemia and from the 1980s also in children with leukemia. Besides having a broad general knowledge of pediatric medicine, Jaak was an international expert in transplantation immunology. He was an intermediate between clinical medicine and more fundamental laboratory immunology. His collaborations were intensive and fruitful. He stimulated the students and fellows to think logically and continuously promoted critical thinking about pathophysiology as basis for optimal treatment of the patient.

From the first beginning of the transplant program in Leiden, there was a strong belief in strict isolation and total gut decontamination to prevent the severe complication graft-versus-host disease (GvHD). To accomplish this, Jaak collaborated with the Radiobiological Institute TNO in Rijswijk. The treatment with so called Julia-flora, with which patients were colonized after the total decontamination, can be called a "fecal transplant" avant la lettre.

With his expertise in immunology, Jaak was involved in the national workgroup for immunodeficiencies (WID) and the Dutch Immunology Association, of which he held the chair between 1989 and 1995. In 1996, he gave the Van Lochem laureate lecture titled "the new cells of the host."

Jaak also played an important role in the initiation and educational support of transplantation teams all over the world. For decades, he was an active and prominent member of the Paediatric Diseases and Inborn Errors Working Party of the European Society of Blood and Marrow Transplantation (EBMT) and the European Society for Immunodeficiencies (ESID). He was also an active member of the European Society for Paediatric Infectious Diseases (ESPID). 
Characteristic for Jaak was the modest and amiable way he was present at these conferences and meetings. Jaak had a true research spirit. The subject of his thesis was the B-lymphocytes, particularly those in the bone marrow. Later, he worked on all kinds of studies encompassing the recovery of immunity after SCT. He was also known for his early work on the $\mathrm{ESID/EBMT}$ patient registry. At meetings, he preferred to stay outside the spotlights and was continuously busy with networking with his co-pioneers. Many of us remember the conversations with Jaak being educative and inspiring moments, even as emeritus. Last autumn, he was a guest of honor sitting in the front row at the meeting in Leiden of the Inborn Errors Working Party of the EBMT/ESID in remembrance of "50year SCT in children."
For his patients, Jaak was an amiable, very pleasant, and expert doctor. He was present at the beginning of stem cell transplantations in children in the Netherlands, to which he made important contributions. He was impressed by and greatly acknowledged the courage of the children and their parents during the SCT course.

We remember him as a true, inspiring, and dear colleague.

Peter Heidt, Hans Rümke, Maarten van Tol, Robbert Bredius, Arjan Lankester

Publisher's Note Springer Nature remains neutral with regard to jurisdictional claims in published maps and institutional affiliations. 